\title{
EDITORIAL
}

\section{Sleep apnoea - evolution and doubt}

\author{
R.R. Grunstein
}

\begin{abstract}
"Why do men hate and despise the doubter? Because doubt is evolution, and society hates evolution because it disturbs the peace." J. August Strindberg (1849-1912). Swedish dramatist.
\end{abstract}

Patients consulting respiratory physicians about snoring and sleep apnoea often ask the question "If I don't have treatment, will my problem get worse?" Such patients may be habitual snorers concerned that they will develop sleep apnoea or mild sleep apnoea patients worried that without treatment, they will descend into an increasing spiral of longer apnoeas and severe hypoxemia resulting in a shorter life. Many of these patients are relatively asymptomatic, perhaps seeking advice following a media story on the dangers of heavy snoring.

The natural history of sleep apnoea has also attracted the interest of researchers virtually from the time sleep apnoea was recognised as a medical condition. The Bologna group was one of the first to develop the concept of snoring and sleep apnoea as part of a spectrum of disease. They advocated that the obstructive sleep apnoea syndrome (OSAS) is a progressive disease which evolves from simple snoring [1]. This "evolution" moves along a spectrum of heavy snoring with intermittent apnoeas (predominantly in rapid eye movement (REM) sleep) eventually progressing to severe disease with respiratory failure in extreme cases. These concepts have been proposed by other groups with relatively long clinical experience with sleep-disordered breathing [2].

Chronic repetitive upper airway obstruction produces distinctive changes in upper airway anatomy, size and neural function [3]. Indeed, prevention of upper airway obstruction with nasal continuous positive airway pressure (CPAP) leads to reversal of some of these apnoea/ snoring induced changes and a decrease in underlying sleep apnoea severity [4]

Therefore, it is somewhat surprising to read in this issue of the Journal a paper by SFORZA and co-workers [5], from Bologna, asserting that OSAS is not a progressive condition. This finding appears to contradict their previous opinion of OSAS as a disorder which becomes more severe with time - or does it? Natural history studies of OSAS are rare. They are difficult to perform for several reasons. Firstly, the study "material" available to most researchers are patients presenting with problems related to OSAS, usually snoring and daytime sleepiness. Such patients cannot be easily randomised to a nontreatment arm of a long-term protocol R. Grunstein, Sleep Disorders Centre, Department of Respiratory Medicine, Royal Prince Alfred Hospital, Sydney Australia 2050. investigating the natural history of sleep apnoea. Patients seek treatment and are typically offered CPAP or upper airway surgery. This problem is highlighted by the selective inclusion of patients who refused treatment for OSAS as the cohort in the study of SFORZA et al. [5]. Secondly, the most meaningful data would involve a large preopsective community cohort with a wide range of sleep apnoea severity and access to full polysomnographic facilities. The expense of such a study would be substantial and requires funding commitments typified by recent $\mathrm{NIH}$ grants to US groups such as the Wisconsin Sleep Cohort [6]. Cross sectional data provided by this US cohort have provided an important "snapshot" of OSAS prevalence. We now know that, at least in middle aged Wisconsin government employees, OSAS (as defined by an apnoea index of more than 5 and daytime sleepiness) occurs in $1 \%$ of men and $2 \%$ of women. This may be an overestimate for European citizens, as Wisconsin has the dubious distinction of having the highest prevalence of obesity in the United States [7]. However, recent data from Milan suggest that the prevalence of OSAS in Italy is not dissimilar from the USA [8]. Our own data from Australia are also in agreement with the Wisconsin data [9]. Thus, OSAS is a relatively common condition and the natural history of the untreated condition has major public health implications. The Wisconsin cohort is currently being followed to prospectively investigate the natural history of sleep apnoea, presumably both controlling for the effect of treatment or other medical intervention in the follow-up period and recording their subjects attempts at preserving their state's reputation in adipose tissue accumulation! However, until the Wisconsin follow-up information is available, we must consider data from smaller and more contentiously designed retrospective studies.

The key findings reported by SFORZA et al. [5] are that, over a 5 yr period, sleep apnoea severity (measured by apnoea frequency or hypoxemia) did not change, severity of the OSAS at baseline did not predict change, and weight gain does not contribute to the evolution of OSAS. However, a close inspection of the presented data suggests that these findings need to be qualified somewhat. The study group was part of a larger group of 100 patients diagnosed with OSA at the University of Bologna. It is unclear if these 100 were a consecutive group or 
were selected in some way. Of the 100 patients, 48 presumably have had treatment (surgery or weight loss of undefined success), leaving 58 for potential followup. The study group of 32 patients consisted of patients who both refused treatment for OSAS at baseline and then consented for polysomnographic follow-up. A further 26 refused sleep study but agreed to clinical interview. It would have been of interest to know the baseline data on subjects from the centre who refused both treatment and any form of follow-up, and thus could not be included in the study. Understanding the mode of selection in natural history studies is crucial to interpretation of data. SForza et al. paper reports that their patients who participated in a follow-up sleep study were less obese than those who refused such investigation. It is also possible that the patients treated with weight loss and not included in the study cohort were more obese than the nontreated group. This may lead to a misunderstanding of the impact of obesity on the evolution of sleep apnoea in this study. Do patients who refuse treatment have distinctive characteristics compared with those that accept therapy? Several studies have suggested that treatment of severe OSAS reduces mortality [10-11]. However, patients who refuse one treatment for one condition, such as OSAS, are arguably likely to refuse treatment for other conditions, such as hypertension or hyperlipidemia, that affect mortality.

In analysing their data, SForza et al. divided their 32 patients into 3 groups based on whether there was a $35 \%$ change in apnoeas and hypopnoeas per hour of sleep (AHI) resulting in the following groups; worsened $(n=6)$, improvers $(n=7)$ and stable $(n=19)$. Interestingly the worsened group consisted of patients who had mild disease at baseline (mean AHI of 9), in contrast to the improvers (mean AHI 56) and stable group (mean AHI 65 ). Thus, patients with mild disease tend to get worse with time. This finding is in keeping with the Bologna group's previous opinion [1], but seems to be underemphasized in the current papers conclusions. Recent data from Sweden [12] also provide support for an evolution from mild to more severe sleep apnoea. The investigators reported baseline and subsequent data on 42 patients with mild OSAS confirmed on polysomnography, who had undergone more limited respiratory monitoring 6-32 months (mean 15 months) earlier. The results showed that there was a doubling in episodes of oxygen desaturation per hour (ODI) from 10 (baseline) to 21 (follow-up). There was a 50\% increase in ODI in $62 \%$ of the patients and a $50 \%$ decrease in ODI in $12 \%$ of patients. This study was retrospective and also based on paired respiratory monitoring rather than polysomnography. However, it is unlikely that such clearcut results were due to a technical error and indeed as the mean baseline ODI was 10, the study is in agreement with SFORZA et al. data showing that worsening of sleep apnoea occurs in patients with milder forms of sleep apnoea.

Patients with more severe forms of sleep apnoea may not be able to increase their apnoea frequency or overall apnoea time due to a "ceiling effect". Apnoea frequency may increase to a point but then further increases in frequency will only occur if individual apnoeas become shorter in duration. The data of SForza et al. suggests that apnoea duration is one variable that increases rather than decreases with time. Alternatively, if apnoea frequency reaches a "ceiling", it is possible that nocturnal hypoxemia (lower oxygen saturation nadirs) may deteriorate. However, again, patients may only tolerate a limited "apnoea/hypoxemia load" determined by a demand to preserve an overall level of normal ventilation during the sleep period. Thus, deterioration may occur only in those with severe obesity, lung disease or abnormal chemoreceptor drive. The patients studied by SFORZA et al. were all eucapnic at baseline, implying relatively intact chemosensitivity. Perhaps only those patients with severe OSAS and altered respiratory drive or lung mechanics develop even more severe OSA over time.

The "worsened" group were also characterised by an increase in Body Mass Index (BMI). Although weight did not change in the "improvers", there is not enough data in Sforza et al's study to exclude weight gain (or loss) as an influence on the evolution of sleep apnoea. Obesity is closely linked to the prevalence of sleep apnoea. Increasing central obesity is associated with increasing severity of OSAS in sleep clinic populations [13] and central fat accumulation increases with age. Central obesity is also enhanced by declining growth hormone levels, a finding noted in both normal ageing and in sleep apnoea [14]. SvANBorg and LARSSON also observed a correlation between weight gain and increase in ODI [12]. However, they also observed patients with large increases in ODI without weight change, implying that other factors may play a role in the evolution of OSAS. Such factors may include smoking [15] or chronic alcohol ingestion [16].

Conversely, why do some people with sleep apnoea reduce their apnoea severity over time? Information is limited, but both recent natural history studies [5, 12] suggest that older patients are more likely to have stable or improved OSAS severity. Is this a "regression" in OSAS as Sforza et al. postulate? Certainly epidemiological studies have observed that ageing has a much lower impact on OSAS prevalence than obesity [6]. Older patients are less likely to be employed or have the busy lifestyle that leads to sleep deprivation and potentiation of sleep-disordered breathing [17]. Ageing in men is also associated with a fall in testosterone levels; could this be protective against further deterioration in apnoea severity? [14].

It is also a mistake to look at the "evolution" of a sleep apnoea purely in terms of respiratory disturbance in sleep. We need data about the cardiovascular and other effects of leaving sleep apnoea untreated. As SFORZA et al. admit, their data in this area are limited. It would seem reasonable practice based on the current limited state of knowledge to continue to follow patients with mild sleep apnoea. Avoidance of weight gain and other potential risk factors for development of OSA should still be advised. However, many of us working in the field of sleep apnoea have been comfortable with the assumption that we are dealing with a condition that progressively worsens over time if untreated. Studies that cast 
doubt on this assumption may make us uncomfortable in answering our patients questions on the natural history of sleep apnoea or on our approach to the asymptomatic patient with repetitive apnoea. This contribution by SFORZA and colleagues on the evolution of sleep apnoea, to use Strindbergs phrase, "disturbs the peace", but rather than "despise the doubter", this study should encourage us to search for more data and better answers to our patients questions.

\section{References}

1. Lugaresi E, Cirignotta F, Gerardi R, Montagna P. Snoring and sleep apnoea: natural history of heavy snorers disease. In: Guilleminault C, Partinen M, eds. Obstructive Sleep Apnea Syndrome. Clinical Research and Treatment, New York, Raven Press 1990: pp. 25-36.

2. Kales A Cadieux RJ, Bixler EO, et al. Severe obstructive sleep apnoea. I. Onset, clinical course, and characteristics. J Chronic Dis 1985; 38: 419-425.

3. Fleetham JA. Upper airway imaging in relation to obstructive sleep apnoea. Clin Chest Med 1992; 18: 399-416.

4. Sullivan CE, Grunstein RR. Continuous Positive Airways Pressure in Sleep Disordered Breathing. In: Kryger MH, Dement WC, Roth T, eds. Principles and Practice of Sleep Disorders. Holt Saunders, 2nd edition 1993.

5. Sforza E, Addati G, Cirignotta F, Lugaresi E. Natural evolution of sleep apnoea syndrome: a five year longitudinal study. Eur Resp $J$ 1994; 7: 1765-1770.

6. Young T, Palta M, Dempsey J, Skatrud J, Weber S, Badr S. The occurrence of sleep-disordered breathing among middle-aged adults. N Engl J Med 1993; 828: 1230-1235.
7. Lantz P, Remington PL. Obesity in Wisconsin. Wisc Med J 1990; 89: 172-176.

8. Ferrini-Strambi L, Zucconi M, Palazzi S, et al. Snoring and nocturnal $\mathrm{O}_{2}$ desaturations in an Italian middle aged population - epidemiological study with an ambulatory device. Chest 1994; 105: 1759-1764.

9. Bearpark HM, Elliot L, Grunstein RR, et al. Occurrence and correlates of sleep disordered breathing in the Australian town of Busselton - a preliminary analysis. Sleep 1993; 16: S3-S5.

10. He J, Kryger MH, Zorick FJ, Conway W, Roth T. Mortality and apnea index in obstructive sleep apnoea. Experience in 385 male patients. Chest 1988; 94: 9-14.

11. Partinen M, Telakivi T. Epidemiology of obstructive sleep apnoea syndrome. Sleep 1992; 15: S1-S4.

12. Svanborg E, Larsson H. Development of nocturnal respiratory disturbances in untreated patients with obstructive sleep apnoea syndrome. Chest 1993; 104: 340343.

13. Grunstein RR, Wilcox I, Yang TS, Hedner J. Snoring and Sleep Apnea in Men Association with Central Obesity and Hypertension. Int J Obesity 1993; 17: 533-540.

14. Grunstein RR. Endocrine and Metabolic Disturbances in Obstructive Sleep Apnoea. In: Saunders NA, Sullivan CE, eds. Sleep and Breathing, Edition 2. New York, Marcel Dekker, 1993.

15. Young T, Watter D. Smoking as a risk factor for sleep apnoea. Am J Resp Crit Care Med 1994; 149: A397.

16. Chan CS, Grunstein RR, Bye PT, Woolcock AJ, Sullivan CE. Obstructive sleep apnea with severe chronic airflow limitation. Comparison of hypercapnic and aucapnic patients. Am Rev Respir Dis 1989; 140: 1274-1278.

17. Stoohs RA, Dement WC. Snoring and sleep-related breathing abnormality during partial sleep deprivation [letter]. N Engl J Med 1993; 328: 1279. 